\title{
PUBLIC HEALTH ENGLAND'S RECOVERY TOOLS: POTENTIAL TEACHING RESOURCES?
}

\author{
A. Peña-Fernández ${ }^{1}$, A. Nisbet ${ }^{2}$, R. Duarte-Davidson², M.C. Lobo-Bedmar ${ }^{3}$, \\ S. Wyke ${ }^{2}$ \\ ${ }^{1}$ De Montfort University, Leicester School of Allied Health Sciences (UNITED KINGDOM) \\ ${ }^{2}$ Centre for Radiation, Chemical and Environmental Hazards, Public Health England \\ (UNITED KINGDOM) \\ ${ }^{3}$ IMIDRA, Departamento de Investigación Agroambiental (SPAIN)
}

\begin{abstract}
Training to combat chemical and radiation accidents, incidents or attacks is critical for health professionals due to recent events involving these hazards or their use as unconventional weapons, such as the use of the nerve agent novichok in Salisbury, UK. Health professionals need to have appropriate knowledge and skills to effectively respond to future events involving any of these substances, which requires a rapid and coordinated response from different professionals to protect the environment and minimise the number of people exposed and reduce morbidity and mortality. However, despite chemical and radiation incidents becoming increasingly prevalent, literature reviews have shown that there is a lack of teaching of appropriate competences to face future crises in Europe, particularly amongst clinicians and other health professionals that would be part of the initial response. Thus, De Montfort University (DMU, UK) in collaboration with different academics from the University of Alcalá (Spain) and researchers from Public Health England (PHE) with comprehensive experience in environmental decontamination and restoration, have created a short training course for providing undergraduate/postgraduate students with basic skills to respond to chemical incidents, basic skills that are based on the major competences recently identified by the European Commission [1]. This novel training has been tested with students from different backgrounds in various European universities, recording high degrees of acquisition of the various basic competences that we developed to initially respond to chemical events [2]. To develop the practical part of this chemical training, we have incorporated the novel guidance and methodology developed by PHE to successfully tailor a protection and recovery response to any incident involving chemical substances, which is available in the "UK Recovery Handbook for Chemical Incidents" [3] and its web-based tools: "Chemical Recovery Navigation Tool" (CRNT, [4]) and "Chemical Recovery Record Form" (CRRF, [5]). These innovative resources aid the user to select effective protection, decontamination and restoration techniques or strategies from a pool of up-to-date options applicable to different environments according to the physicochemical properties of the chemical(s) involved and the area affected. The CRNT is accompanied by the CRRF, which facilitates collection and analysis of the necessary data to inform decisions, and an e-learning resource named "Chemical Recovery: Background" (CRB, [6]), which could facilitate the learning of environmental decontamination and restoration. We are currently developing a short training course to cover minor radiation incidents; this radiation training will follow the same methods used to develop the chemical training, but with the specific PHE recovery tools to tackle such events, specifically the "UK Recovery Handbooks for Radiation Incidents" [7] and its associated web-based tools "Radiation Recovery Navigation Tool" (Rad RNT, [8]), one for each environment: food production systems, inhabited areas and drinking water supplies. This communication will explore the use of the PHE's Recovery Navigation Tools as potential resources to facilitate the acquisition of basic knowledge to tailor protection and recovery interventions for minor chemical and radiation incidents to protect the public.
\end{abstract}

Keywords: Chemical recovery, radiation recovery, PHE recovery tools, training, response.

\section{INTRODUCTION}

The release of chemical, biological, radiological, and nuclear (CBRN) substances, and other hazardous material (HazMat) into the environment, either deliberately or involuntarily, are termed CBRN and explosive (CBRNe) or HazMat incidents, respectively. CBRN incidents, although rare, can impact on large groups in a population and affect multiple countries simultaneously, with serious implications for human health and the environment $[9,10]$. Examples of HazMat/CBRNe incidents are the attack with the highly toxic and environmentally persistent novichok agent in Salisbury (UK) in 2018 [11,12], the use of warfare chemical agents used against Syrian population [13] or the accident in the Fukushima Daiichi Nuclear Power Plant in 2011 in Japan [14]. 
HazMat/CBRNe incidents require an appropriate and immediate international collaborative response from different experts, health professionals and authorities to protect the public [15], which can represent an enormous challenge for countries without specific tools, resources, trained personnel and infrastructures. Moreover, large events involving these substances can seriously affect and collapse healthcare systems in developed countries, highlighting the need to prepare nations against CBRN threats [16].

Literature reviews have shown that specific training to respond to future crises involving CBRN substances is only offered in a few healthcare programmes, mostly in the United States (US) [17]. There is also very little peer-reviewed literature or guidelines that provide an outline of specific learning objectives and activities to implement and deliver this training to face future crises; particularly amongst clinicians and other health professionals that would be part of an initial response [15]. However, it is imperative that health professionals that will be the first-response workforce, i.e. nurses, doctors, paramedics, biomedical scientists, physician associates, and public health officers, have the necessary skills to effectively respond to HazMat/CBRN threats [17].

\section{RECOVERY AND RESTORATION}

A multi-faceted process is needed to respond to CBRN incidents to protect human health. The preliminary response during the acute phase is usually coordinated and managed by first responders including police, fire and rescue personnel, medics and paramedics. Local, national or international responses may be needed depending on the scale of the incident [9]. Moreover, appropriate intervention programmes should also consider the decontamination and restoration of the environment(s) affected [18].

\subsection{UK Recovery Handbooks}

In the UK, Public Health England (PHE), an executive agency of the Department of Health committed to continue to maintain and update guidance and advice for environmental recovery and remediation, has created a series of innovative resources and guidance, named UK Recovery Handbooks, with support from other UK's Government Departments and Agencies, to facilitate and guide recovery decision-makers through the process of tailoring their recovery strategy. Currently, there are three UK Recovery Handbooks available, for chemical (UKRHCl; [3]), biological (UKRHBI; [19]), and radiation incidents (UKRHRI; [7]), which are freely accessible from the PHE website (Fig1): https://www.gov.uk/ government/collections/recovery-remediation-and-environmental-decontamination. The UK Recovery Handbooks have covered a gap in the literature and have been designed to be user-friendly technical guidance documents with innovative decision frameworks for identifying and evaluating effective up-todate recovery strategies.

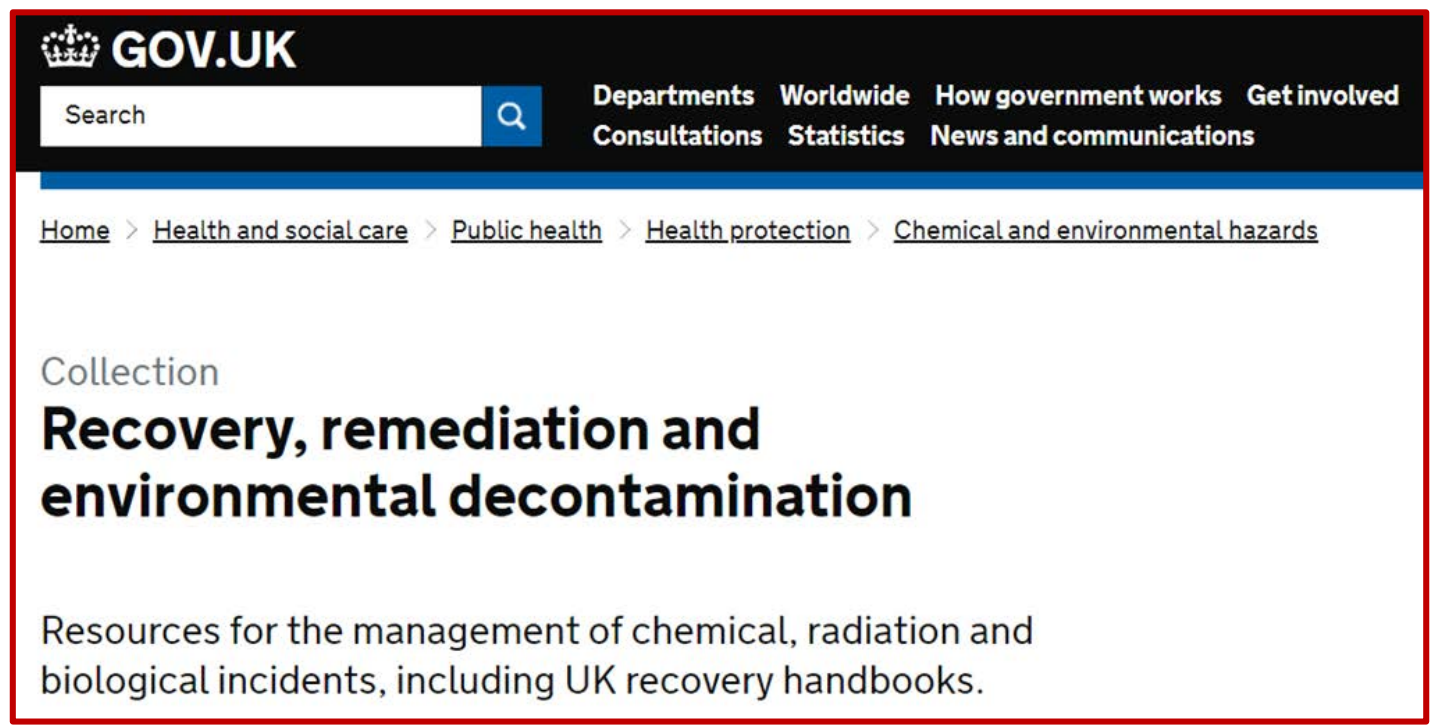

Figure 1. Overview of PHE recovery website. Available at: https://www.gov.uk/government/collections/recovery-remediation-and-environmental-decontamination 
The first of its kind was the UK Recovery Handbook for Radiation Incidents (version 1; [20]), which was prompted by an accident at the Chernobyl Nuclear Power Plant, Ukraine in 1986 [21]. This Handbook has been updated on different occasions to incorporate new information and to introduce a stepwise approach to selecting and combining recovery options. The third version of the UKRHRI (published in 2009) was subsequently used as a basis for developing the UKRHCl, which in turn was used for developing the UKRHBI. The three UK Recovery Handbooks incorporate lessons learned from previous incidents and include a robust evidence base for the recovery/management options recommended for three different environments: food production systems, inhabited areas and water environments (only drinking water systems for the UKRHRI) [22].

\subsection{PHE Recovery Tools}

As a consequence of the UK Recovery Handbooks, and to facilitate and guide recovery decision-makers through the process of tailoring their recovery strategy when responding to any given chemical or radiation incident, PHE has produced two innovative website resources, named Recovery Navigation Tools, for Chemical (CRNT; Fig 2; [4]) and Radiation incidents (Rad RNT; [8]). These RNTs are highly interactive web-based resources, which follow the same methodology and guidance described in their respective UK Recovery Handbooks. They are more efficient during the tailoring of a recovery plan, as they have been built using standard templates within a linked framework that it is easy to follow and is accessible from any web-enabled devices (Fig. 2).

The PHE RNTs includes a downloadable recovery record form (RRF), one for each tool, as a means of capturing the underlying rationale for decisions on the selection of options, thereby serving as an audit trail. Additionally, the CRNT is accompanied by an e-learning resource named "Chemical Recovery: Background" (CRB, [6]) that provides information on environmental decontamination and restoration.

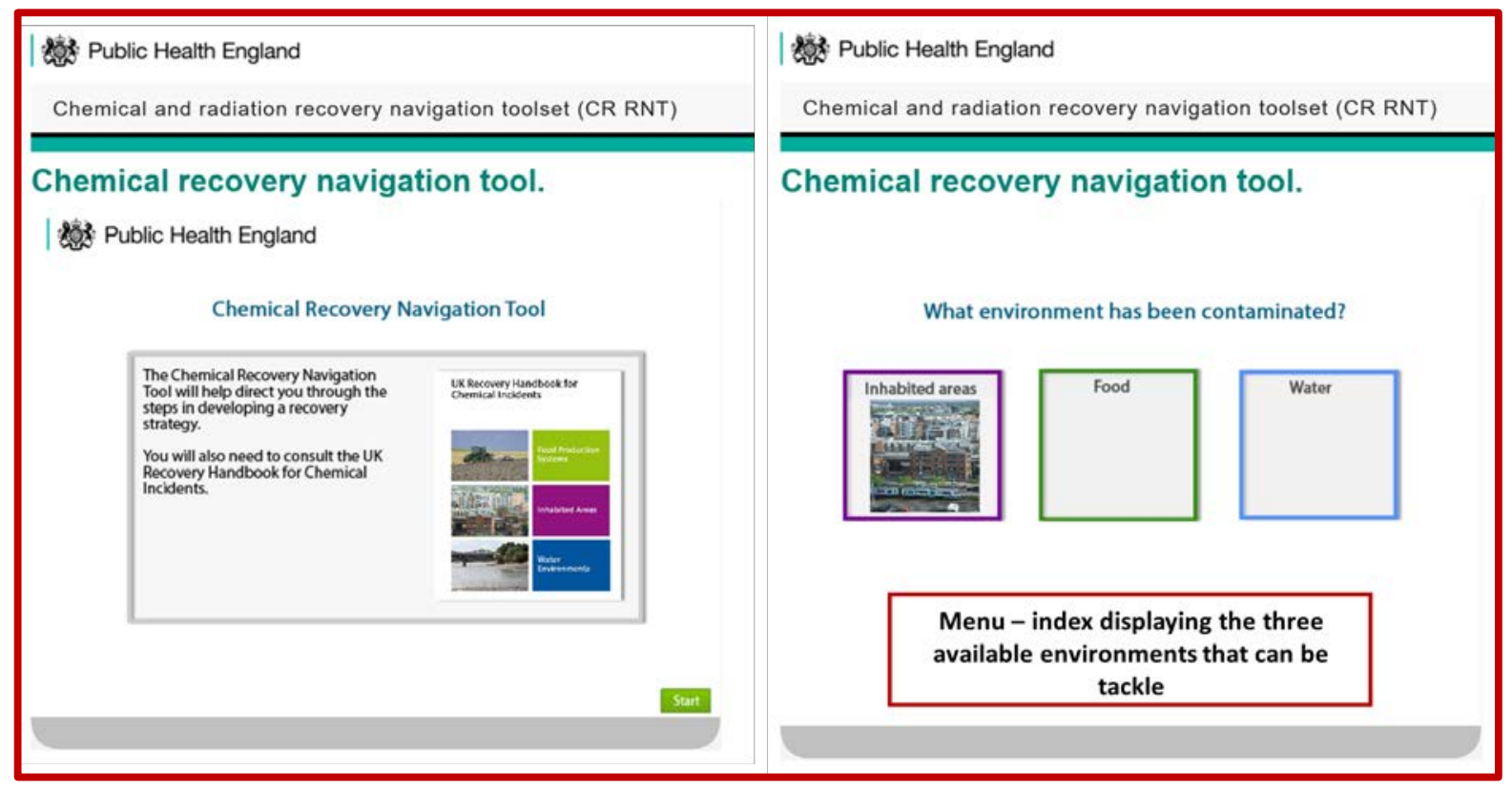

Figure 2. Overview of PHE's CRNT. Available at: http://legacyassets.phe.org.uk/tools/CRT_elearning/index.html

\section{METHODS}

In order to address the lack of relevant training to respond to these events in European health programmes, a group of academics from De Montfort University (DMU, Leicester, UK) and University of Alcalá (UAH, Spain), have developed a novel practical training to provide students with basic competences to initially respond to chemical incidents $[23,24]$. This novel training covers the different phases of a response described by Sandström et al. (2014) [25]: 1) incident response preparedness and situation assessment; 2) exposure assessment; 3) acute health effects; 4) long term health effects; and 5) recovery phase. The tailored basic competences are based on the major competences identified by the European Commission in the CBRN Threat Identification and Emergency Response project [1], and have been described previously by our team in Peña-Fernández (2019) [26]. 
To date, the chemical recovery training is composed of two short courses, which cover most of the basic competences tailored:

- Design a public health programme to prevent exposure of children to $\mathrm{Pb}$ in an urban environment (2 hours).

- Environmental decontamination, recovery and restoration of an area impacted by emerging chemical pollutants (2 hours).

Both short courses have been tested with undergraduate and postgraduate students for different programmes at DMU in the UK, and at the Spanish Universities of Alcalá and San Pablo CEU (USPCEU). We have used qualitative and quantitative methods, included a validated feedback-questionnaire with Likert scale and free-response questions, to measure the effectiveness of the chemical recovery training. Ethical approval was provided by the Research Ethics Committee at De Montfort University (Ref. 1729) and from the Ethics Committee at the USP-CEU (Ref. 143/17/01).

\section{RESULTS AND DISCUSSION}

The results of the training have been analysed and described previously by our group. In general, although further development and testing is required to produce a complete training programme that covers all the competences created. The developed methods and resources could be useful to implement training in these topics in any human health degree, after appropriate adaptation.

Students' responses regarding the use of the PHE Chemical Recovery Tools, i.e. the CRNT and $\mathrm{UKRHCl}$, to respond to the second short training course developed following successful educational training implemented at the University of Alcalá [23], which have not been published in its all detailed before, are collected in Table 1.

While our results should be considered as preliminary due to the low number of students that voluntarily provided feedback after our training, nevertheless students from both programmes (undergraduate and postgraduate) were able to complete and restore the contaminated scenario provided using the PHE Recovery Tools. Thus, despite the short time available, they were able to identify the contaminated environment and possible sources of exposure. Students also selected applicable protection (e.g. control of entry into food chain; precautionary advice; ban on fishing) and recovery options (e.g. incineration) to remediate the scenario proposed. With respect to their appreciation of the PHE Recovery Tools, their favourite was the CRNT, although undergraduate students found it difficult to understand (Table 1). The use of the different e-learnings resources created by PHE, specifically the CRB and the recovery tools e-learning module [27], could facilitate undergraduate students to become familiar with the PHE recovery tools and acquire some basic environmental knowledge.

Table 1. Overview of students' responses on the PHE recovery tools and resources used to complete second short training course at USP-CEU (Spain) and DMU (UK).

\begin{tabular}{|c|c|c|c|c|}
\hline & $\begin{array}{l}\text { Programme, university } \\
\text { arena, number of } \\
\text { students responded } \\
\text { questionnaire \& } \\
\text { academic year }\end{array}$ & $\begin{array}{l}\text { PHE tools aid my } \\
\text { learning about } \\
\text { recovery and } \\
\text { restoration (\%) }\end{array}$ & $\begin{array}{c}\text { CRNT was easy to } \\
\text { understand (\%) }\end{array}$ & Constraints \\
\hline Undergraduate & $\begin{array}{l}\text { Pharmacy } \\
\text { USP-CEU } \\
(n=14 ; 2016 / 17)\end{array}$ & $\begin{array}{l}100 \% \text { agreed } \\
(85.7 \% \text { agreed, } 14.29 \% \\
\text { strongly agreed })^{1}\end{array}$ & $\begin{array}{l}42.9 \% \text { strongly } \\
\text { disagree; } 57.1 \% \text { neither } \\
\text { agreed nor disagree* }\end{array}$ & $\begin{array}{l}\text { Some concepts were } \\
\text { difficult to understand. } \\
\text { CRRF: some hyperlinks } \\
\text { were not working }\end{array}$ \\
\hline \multirow{2}{*}{ Postgraduate } & $\begin{array}{l}\text { MSc Advanced } \\
\text { Biomedical Science } \\
\text { DMU } \\
(n=6 ; 2016 / 17)\end{array}$ & $100 \%$ agreed & $100 \%$ agreed & None \\
\hline & $\begin{array}{l}\text { MSc Advance } \\
\text { Biomedical Science } \\
\text { DMU } \\
(n=9 ; 2018 / 19)\end{array}$ & $\begin{array}{l}100 \% \text { agreed } \\
(66.7 \% \text { agreed, } 33.3 \% \\
\text { strongly agreed) }\end{array}$ & $\begin{array}{l}100 \% \text { agreed } \\
\text { (44.4\% agreed, } 55.6 \% \\
\text { strongly agreed) }\end{array}$ & None \\
\hline
\end{tabular}

${ }^{1}$ Absence of data regarding Likert category indicates no responses for that category and/or all responses for the indicated category. *Data collected from Peña-Fernández (2019) [24]. 
Although not described in this communication, our group found similar results when delivering CPD training on the PHE Chemical Recovery tools to real first responders including police and environmental officers, who have identified the CRNT as an easy-to-use resource to tailor protection and decontamination responses to chemical incidents. Additionally, similar feedback regarding the tools has been collected from academics that attended a recent workshop on how to use the PHE's Chemical Recovery Tools to deliver training to respond to chemical incidents in healthcare programmes that our team delivered at the "Advance Higher Education Teaching and Learning conference 2019" [28] in the UK.

\subsection{What's next?}

Our innovation teaching group will undertake the following developments to improve the recovery training:

- Creation of video-tutorials on the demonstration of the use of the different PHE Chemical Recovery Tools, the UKRHCl and CRNT, so end-users can familiarise themselves with the practical use of these resources. This development is a response to the feedback provided by DMU postgraduate students this academic course (2018/19), who have pointed out the possibility of developing videos on YouTube that demonstrate the use of these resources.

- Developing a new short training course to cover minor radiation incidents, following the same methods used to develop the chemical recovery training. To develop this training, we will use the specific PHE Radiation Recovery Tools.

\section{CONCLUSIONS}

The PHE chemical recovery tools are valuable teaching resources. Students from different university arenas and backgrounds were able to select logic recovery options or actions to remediate the different scenarios proposed. Undergraduate and postgraduate students chose the CRNT as their favourite tool over the UKRHCl, which was logical due to the higher level of interactivity and engagement that the RNT offers. The methods and resources used, specifically the different PHE recovery tools, could be useful to implement training to respond to CBRN events in any human health degree as well as to create CPD training to future healthcare professionals that will possibly respond to these events. Additionally, these PHE resources can be used in other countries, after appropriate adaptations, following local needs, area characteristics and legislations.

\section{ACKNOWLEDGEMENTS}

The authors would like to thank the Erasmus+ staff mobility funds granted (2016-17) to Dr. PeñaFernández, which were used to deliver the chemical recovery training in USP-CEU. Additionally, the authors would like to thank Project FERTILIX 2019 (IMIDRA) for their contribution to this project.

\section{REFERENCES}

[1] Djalali A, Della Corte F, Segond F, Metzger MH, Gabilly L, Grieger F, Larrucea X, Violi C, Lopez $C$, Arnod-Prin P, Ingrassia PL. TIER competency-based training course for the first receivers of CBRN casualties: a European perspective. Eur J Emerg Med 2017; 24(5):371-376.

[2] Peña-Fernández A., Dunford LJ., Haris PI., Lobo-Bedmar MC., Peña MA. Harmonising the training of students within the EU to implement intervention programmes to protect the public in the aftermath of a HazMat incident. ICERI2016 Proceedings 2016; pp. 3559-3565. Available at: https://library.iated.org/view/PENAFERNANDEZ2016HAR [accessed 25/09/2019]

[3] Wyke-Sanders S, Brooke N, Dobney A, Baker D,Murray V. The UK Recovery Handbook for Chemical Incidents. ISBN 978-0-85951-717-1. Available at: https://www.gov.uk/government/publications/uk-recovery-handbook-for-chemical-incidents-andassociated-publications [accessed 25/09/2019]

[4] PHE, 2015. Chemical recovery navigation tool (CRNT). Available at: https://www.gov.uk/government/publications/chemical-and-radiation-recovery-navigation-tool-crrnt [accessed 25/09/2019] 
[5] PHE, 2015. Chemical recovery record form (CRRF). Available at: https://www.gov.uk/government/publications/chemical-recovery-record-form-crrf-food-inhabitedareas-and-water-environment [accessed 25/09/2019]

[6] PHE, 2015. Chemical recovery: background (CRB). Available at: http://legacyassets.phe.org.uk/tools/CRT_elearning/index2.html [accessed 25/09/2019]

[7] Nisbet A., Watson S., Brown J. The UK Recovery Handbook for Radiation Incidents Version 4, 2015. ISBN 978-0-85951-767-6. Available at: https://www.gov.uk/government/publications/ukrecovery-handbooks-for-radiation-incidents-2015 [accessed 25/09/2019].

[8] PHE, 2015. Radiation recovery navigation tool (Rad RNT). A Rad RNT for each main environment is available at: https://www.gov.uk/government/collections/recovery-remediation-andenvironmental-decontamination [accessed 25/09/2019]

[9] Duarte-Davidson R., Orford R., Wyke S., Griffiths M., Amlôt R., Chilcott R. Recent advances to address European Union Health Security from cross border chemical health threats. Environ Int 2014; 72:3-14.

[10] Calamai F., Derkenne C., Jost D., Travers S., Klein I., Bertho K., Dorandeu F., Bignand M., Prunet $B$. The chemical, biological, radiological and nuclear (CBRN) chain of survival: a new pragmatic and didactic tool used by Paris Fire Brigade. Crit Care. 2019; 23(1):66.

[11] Vale JA., Marrs TC OBE., Maynard RL CBE. Novichok: a murderous nerve agent attack in the UK. Clin Toxicol (Phila) 2018; 14:1-5.

[12] Schumacher J., Arlidge J., Dudley D., Van Ross J., Garnham F., Prior K. First responder communication in CBRN environments: FIRCOM-CBRN study. Emerg Med J 2019; 36(8):456458.

[13] Note by the Technical Secretariat. Organisation for the Prohibition of Chemical Weapons. Report of the opcw fact-finding mission in syria regarding alleged incidents in Itamenah, the Syrian Arab Republic 24 and 25 March 2017. 2018; 1636.

[14] Tsubokura M., Murakami M., Takebayashi Y., Nomura S., Ono K., Ozaki A., Sawano T., Kobashi Y., Oikawa T. Impact of decontamination on individual radiation doses from external exposure among residents of Minamisoma City after the 2011 Fukushima Daiichi nuclear power plant incident in Japan: a retrospective observational study. J Radiol Prot. 2019; 39(3):854-871.

[15] Olivieri C., Ingrassia PL., Della Corte F., Carenzo L., Sapori JM., Gabilly L., Segond F., Grieger F., Arnod-Prin P., Larrucea X., Violi C., Lopez C., Djalali A. Hospital preparedness and response in CBRN emergencies: TIER assessment tool. Eur J Emerg Med 2017; 24(5):366-370.

[16] Singh VK., Garcia M., Wise SY., Seed TM. Medical countermeasures for unwanted CBRN exposures: Part I chemical and biological threats with review of recent countermeasure patents. Expert Opin Ther Pat 2016; 26(12):1431-1447.

[17] Kako M., Hammad K., Mitani S., Arbon P. Existing Approaches to Chemical, Biological, Radiological, and Nuclear (CBRN) Education and Training for Health Professionals: Findings from an Integrative Literature Review. Prehosp Disaster Med 2018; 33(2):182-190.

[18] Wyke S, Peña-Fernández A, Brooke N, Duarte-Davidson R. The importance of evaluating the physicochemical and toxicological properties of a contaminant for remediating environments affected by chemical incidents. Environ Int 2014; 72:109-18.

[19] Pottage T., Goode E, Shieber C., Wyke S., Speight S., Bennett AM. UK Recovery Handbook for Biological Incidents 2015. ISBN 978-0-85951-777-5. Available at: https://www.gov.uk/government/publications/uk-recovery-handbook-for-biological-incidents [accessed 25/09/2019].

[20] Health Protection Agency, HPA. UK Recovery Handbook for Radiation Incidents. HPA-RPD-002 (ISBN 0-85951-559-1), 2005.

[21] Nisbet AF., Brown J., Howard BJ., Beresford NA., Ollagnon H., Turcanu C., Camps J., Andersson K., Rantavaara A., Ikäheimonen T., Duranova T., Oughton D., Kirchner G., Papachristodoulou C., loannides K., Kwakman P. Decision aiding handbooks for managing contaminated food production systems, drinking water and inhabited areas in Europe. Radioprotection 2010; 45(5):S23-S37. 
[22] Nisbet A., Watson S., Peña-Fernández A., Wyke S. Updates to the UK Recovery Handbook for Radiation Incidents. Chemical Hazards and Poisons Report 2015; 25:20-22.

[23] Peña-Fernández A., González-Muñoz MJ., Peña MA. Designing training for teaching environmental toxicology to specialized pharmacists. Currents in Pharmacy Teaching and Learning 2015; 7:864-868.

[24] Peña-Fernández A. Teaching environmental decontamination and restoration. Medical Education, 2019; 53(5):523-524.

[25] Sandström BE, Eriksson H, Norlander L, Thorstensson M, Cassel G. Training of public health personnel in handling CBRN emergencies: a table-top exercise card concept. Environ Int 2014; 72:164-9.

[26] Peña-Fernández A. Undergraduate training to respond to chemical and biological incidents. In: Al futuro con el pasado: X Encuentro de Innovación en Docencia Universitaria. Eds. Del Castillo Fernández H. and Gómez Hernández P. Alcalá de Henares: Servicio de Publicaciones de la Universidad de Alcalá, 2019: pp. 451-460. ISBN: 978-84-17729-88-2. Available at: https://www3.uah.es/ice/ID/publicaciones_id.html [accessed 25/09/2019]

[27] PHE, 2015. UK recovery handbooks and tools for remediating the environment after a chemical or radiation incident. Available at: https://www.gov.uk/government/publications/chemical-andradiation-incidents-recovery-handbooks-and-tools [accessed 25/09/2019]

[28] Peña-Fernández A., Lobo-Bedmar C., Duarte-Davidson R., Wyke S. Novel training for undergraduates to respond to chemical incidents or attacks. Advance Higher Education Teaching and Learning conference 2019, Newcastle upon Tyne, UK, 2nd to 4th July 2019. Workshop presentation. Available at: https://www.heacademy.ac.uk/node/38404 [accessed 25/09/2019] 